\title{
Comparative evaluation of the ultrastructural morphology and distribution of filiform and fungiform tongue papillae in Egyptian mice, fruit bats and long-eared hedgehogs
}

\author{
Tahany Haggag ${ }^{1}$, Elham F. Mahmoud ${ }^{2}$, Zeinab A. Salem ${ }^{1,3}$, Nermeen AbuBakr $^{1}$ \\ ${ }^{1}$ Department of Oral Biology, Faculty of Dentistry, Cairo University, Cairo, ${ }^{2}$ Department of Oral Biology, Faculty of Oral and Dental Medicine, Suez \\ Canal University, Ismaelia, ${ }^{3}$ Department of Oral Biology, Faculty of Oral and Dental Medicine, Ahram Canadian University, Cairo, Egypt
}

\begin{abstract}
The tongue is a specialized vital organ. It aids in mastication, deglutition and food digestion. It also shares in the perception of taste sensation as it possesses various gustatory papillae. It is being subjected to numerous anatomical and histological examinations aiming at exploring the correlation between its morphological features and animal adaptations to various types of nutrition and environmental conditions. The goal of the present work was to compare the ultrastructural features of the filiform and fungiform papillae of three various mammals possessing different feeding habits; Egyptian mice, fruit bats and long-eared hedgehogs. Specimens were obtained from the tongues of four healthy adult animals from each mammalian type. Tongues were fixed and all the appropriate procedures were done to perform scanning electron microscopic investigation. Scanning electron microscopic examination demonstrated that in mice, there were four different sub-types of filiform papillae (spike, leaf, conical and tongue-shaped). In bats, there were two sub-types (flower and leaf-like) and in hedgehogs, there was only one type (tongue-like). These filiform papillae showed different distribution and orientation. As for the fungiform papillae, they were cylindrical in mice, rounded or conical in bats and dome-shaped in hedgehogs. Fungiform papillae possessed taste pores containing taste buds. Ultrastructural variations of the filiform and fungiform papillae were suggested to be probably due to adaptation to various feeding habits and different environmental conditions of these animals.
\end{abstract}

Key words: Tongue, Mice, Chiroptera, Hedgehogs

Received July 9, 2020; Revised September 6, 2020; Accepted September 15, 2020

\section{Introduction}

In mammals, the tongue is a pivotal tactile organ that contributes markedly to food sensation. It is highly affected by nutritional habits and that's why it differs in form, dimen-

\section{Corresponding author:}

Nermeen AbuBakr (iD

Department of Oral Biology, Faculty of Dentistry, Cairo University, Cairo 11553, Egypt

E-mail: nermeen.abubakr@dentistry.cu.edu.eg sions and morphology [1]. Several studies have examined the tongues of numerous species of animals not only for how they affect taste sensation but also for their role in food palatability, liquid food intake, chewing, mingling food with saliva, sucking habit, swallowing and speaking [2].

The adaptability of vertebrates to the surrounding environment greatly depends on their feeding mechanisms [3]. The tongue and hypobranchial system are responsible for a broad diversity of functions like prey capture, respiration, liquid intake and defense mechanism [4]. Furthermore, there is a highly significant correlation between tongue's anatomy, morphology and the environmental circumstances in which 
animals utilize their tongues or hypobranchial system [5].

The shape and structure of the tongue vary greatly among animal species, reflecting the different functions of each particular tongue [6]. Tongue anatomy revealed three parts which are apex, body and root [7]. In mammals, four different categories of tongue papillae (filiform, fungiform, circumvallate, and foliate) could be identified on its dorsal surface [8]. Tongue morphology shows a big difference in its structural features according to dietary habits and taxonomy [9].

Rodents are the largest order of mammals. Mice belong to the Mammalia class, order Rodentia, family Muridae [10]. They are omnivorous rodents. They consume both plants and animals and are capable of adapting to local available resources [11].

Bats are the second largest order of mammals. They are arboreal animals. They belong to the Chiroptera order. The Order Chiroptera is divided into two suborders; the Megachiroptera (megabats) which includes one family (the Pteropodidae) and the Microchiroptera (microbats) which includes 18 families [12]. There are various morphological differences between the two suborders; megabats are mostly phytophagous, while microbats are almost carnivorous, particularly insectivorous. Moreover, the basic aspects of kinematics and behavior are significantly different between both suborders $[12,13]$. The fruit bats are megabats, belonging to suborder Megachiroptera, family Pteropodidae. Pteropodidae feed on fruits, flowers, nectar and pollen and have Rousettus genus. Rousettus aegyptiacus is the only species of bats present in Egypt [14].

The long-eared hedgehog, Hemiechinus auritus, is one of the species of spiny hedgehogs. It belongs to family Erinaceidae, order Insectivora [15]. It is found in the Middle East, in the deserts of Egypt and Libya [16]. It is an earthly nightly mammal which lives in cultivated habitats as farms and gardens. The long-eared hedgehog is insectivorous, mostly feeds on small invertebrates and worms [17]. Hedgehogs possess a muscular tongue that occupies most of the oral cavity [18]. Their blood can be used to treat various diseases and their flesh can be eaten as a kind of remedy to certain illnesses [19].

Accordingly, this study has been carried out to compare the ultrastructure and distribution of the filiform and fungiform papillae on the dorsal surface of the tongues in three various animals from three distinct species of mammals (Egyptian mice, fruit bats and long-eared hedgehogs) which are characterized by a great diversity of dietary habits.
Moreover, the purpose of this research was to clarify the correlation between the morphology and distribution of tongue papillae of these mammals and their feeding habits.

\section{Material and Methods}

\section{Experimental animals}

Four adult normal healthy animals of both sexes (2 males and 2 females) from each mammalian type; Egyptian mice, fruit bats and long-eared hedgehogs were obtained from $\mathrm{Abu}$ Rawash farm, Giza, Egypt. All procedures were conducted in accordance with local ethical rules.

\section{Scanning electron microscope preparation}

Animals were euthanized by ketamine overdose. Tongues were dissected from the root. Tongues were fixed into $3 \%$ glutaraldehyde with phosphate buffer ( $\mathrm{pH}$ 7.3). Tissue samples were rinsed in buffer, then post-fixation was carried out in $1 \%$ osmium tetroxide $(\mathrm{OsO} 4)$ at $37^{\circ} \mathrm{C}$ for 1.5 hours. Afterwards, the post-fixed specimens were put in $3 \mathrm{~N} \mathrm{HCl}$ at $60^{\circ} \mathrm{C}$ for 20 minutes to eliminate extracellular mucus from the tissue surface. The specimens were passed through alcohol and amyl acetate series and their dryness was achieved with critical-point-dryer. The dried samples were covered by a gold sputter coater (SPI-Module; SPI Supplies, West Chester, PA, USA) and specimens were examined by JEOL-JSM-5500 LV (JEOL, Ltd., Akishima, Tokyo, Japan) reflection scanning electron microscopy at the National Research Center, Cairo, Egypt. The specimens were stored over silica gel to remain in perfect condition for many weeks.

\section{Results}

\section{Scanning electron microscopic observations}

\section{Egyptian mice tongue}

The dorsal surface of mice tongue revealed four various sub-types of filiform papillae. These papillae were numerous and extended throughout its entire surface. Spike-shaped filiform papillae were arranged in parallel rows at the middle area of the tongue especially on both sides of the median sulcus. The papillae that were close to the median sulcus were directed towards the sulcus. Great numbers of conicalshaped filiform papillae were observed. Some of them were observed at the tip and directed posteriorly towards the root of the tongue whereas others existing at the lateral sides of 

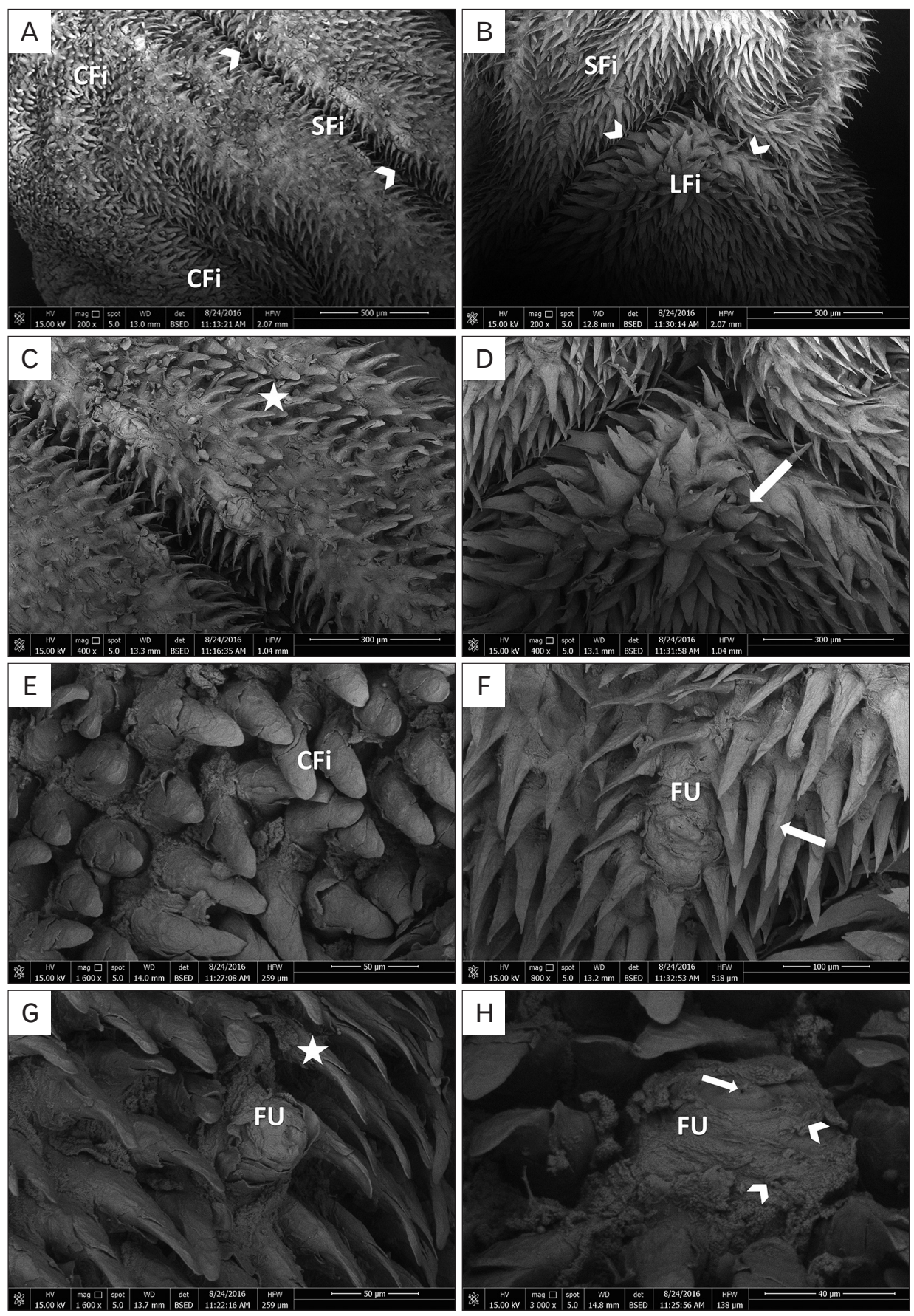

Fig. 1. Scanning electron micrograph of dorsal surface of mice tongue showing (A) SFi arranged in both sides of the median sulcus (arrowheads) and CFi at the tip and lateral sides of the tongue. (B) SFi, LFi with terminal processes and v-shaped sulcus (arrowheads). (C, D) tongue-shaped filiform papillae (star), overlapped leaf-shaped filiform papillae with two or three terminal processes of papillae tips (arrow). (E) thickened CFi overlapping each other. (F) FU in between numerous SFi (arrow). (G) tongue shaped filiform papillae (star) and FU. (H) FU with micro-pits, micro-ridges (arrowhead) and taste pore (arrow). CFi, conical-shaped filiform papillae; FU, fungiform papillae; LFi, leaf-shaped filiform papillae; SFi, spiked shaped filiform papillae.

the tongue were directed medially (Fig. 1A). Posteriorly, a V-shaped sulcus was evident with two shapes of filiform around it, leaf-shaped filiform papillae with two or three terminal processes (bifid or trifid) and spike- shaped filiform papillae. Both papillae were directed towards the V-shaped sulcus (Fig. 1B). Another shape of the filiform papillae was observed and appeared as tongue-shaped and was directed posteriorly (Fig. 1C). By higher magnification, overlapped layers of leaf-shaped filiform papillae were evident and the tip of each papilla was divided into two or three terminal processes (Fig. 1D). Conical-shaped filiform papillae were numerous and appeared thickened with rounded ends (Fig. 1E). Cylindrical-shaped fungiform papillae was noted in between the spike or tongue-shaped filiform papillae. Higher magnification of the surface epithelium of the fungiform papillae also revealed micro-pits, micro-ridges and taste pore, 

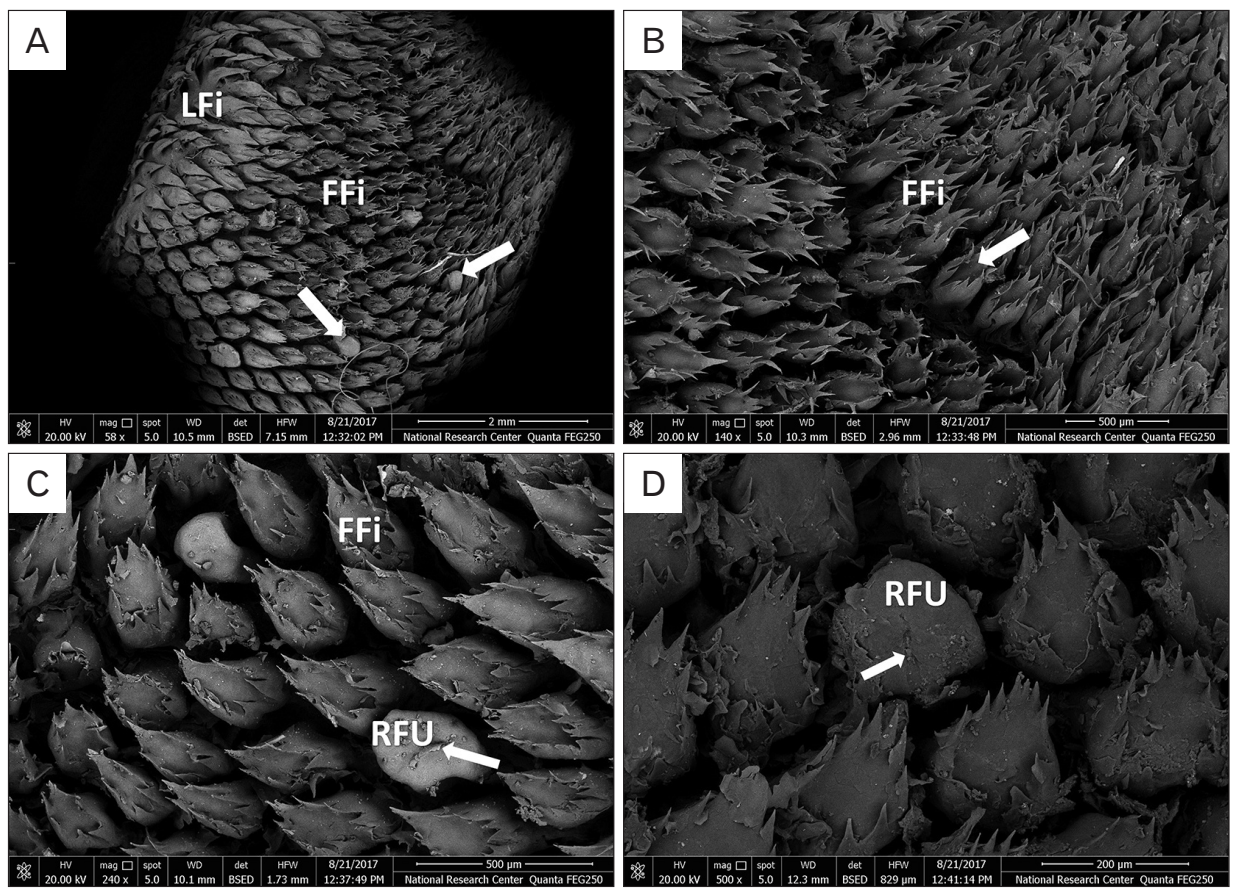

Fig. 2. Scanning electron micrograph of filiform and FU of bats showing (A) leaf-like filiform papillae (LFi) overlapping each other at the lateral sides of the tongue, an abundant number of FFi throughout the whole surface of the tongue and scattered
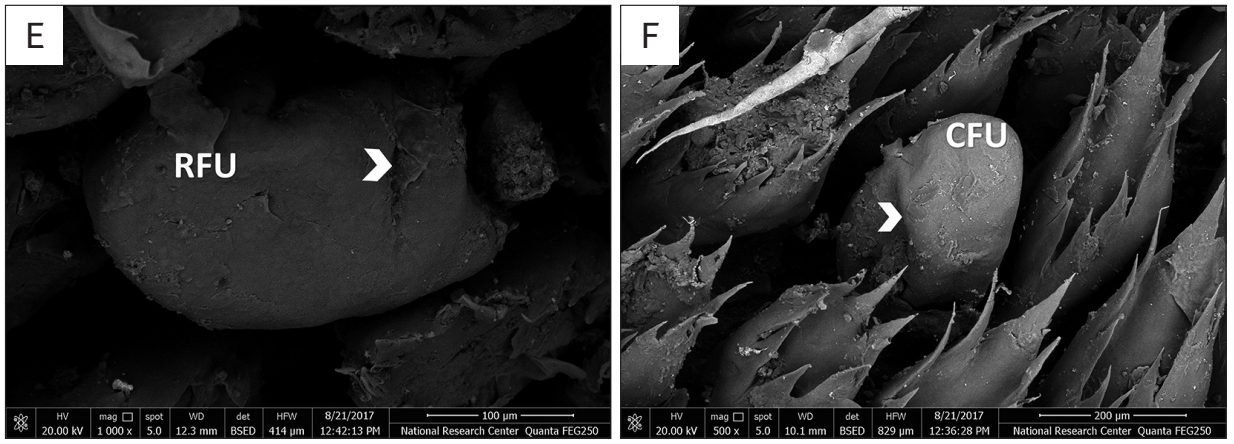
FU (arrows). (B) FFi with its multiple apical processes (arrow). (C, D) RFU present between the FFi and elevated parts and microgrooves of FU (arrows). (E) RFU and surface microgrooves (arrow head) that contain the taste pore. (F) CFU scattered in between the filiform papillae with its depressed side wall (arrow head). CFU, conical shaped fungiform papillae; FFi, flower-shaped filiform papillae; FU, fungiform papillae; LFi, leaf-like filiform papillae.

all were present on epithelial cell surfaces (Figs. 1F-H).

\section{Fruit bats' tongue}

The tongue of bat was rectangular in shape with an elongated body and a widened root. The filiform papillae were plentiful and distributed throughout its entire dorsal surface. The shape, size and direction of these papillae and their processes were variable and depended on their places within the tongue. The papillae near the median portion were slightly posteriorly directed towards the root of the tongue, while those occupying the lateral parts of tongue were directed medio posteriorly. There were two subtypes of filiform papillae on the dorsal surface of the tongue; flower-like and leaflike filiform papillae. There were few numbers of fungiform papillae distributed between the filiform papillae (Fig. 2A). The flower-shaped filiform papillae showed a unique morphology. They possessed posteriorly oriented numerous tapered processes which extended from all upper borders of the papillae. These flower-shaped papillae were proved to aid in food retention and gripping on fruits (Fig. 2B). The fungiform papillae were scattered among the filiform papillae and revealed two categories according to their form; the first form was round-shaped and characterized by small round depressions on the surface, elevated parts and microgrooves. Taste pore of the taste bud was present in the microdepressed portion or the microgrooves (Figs. 2-E), while the second form of the papillae was the conical-shaped, with a depression or concave area on its sidewall (Fig. 2F).

\section{Long-eared-hedgehogs' tongue}

The tongue of hedgehog appeared rectangular in shape with an elongated body and a widened root. Shallow grooves were observed laterally with the absence of the median sulcus on its dorsal surface. The filiform papillae were extend- 

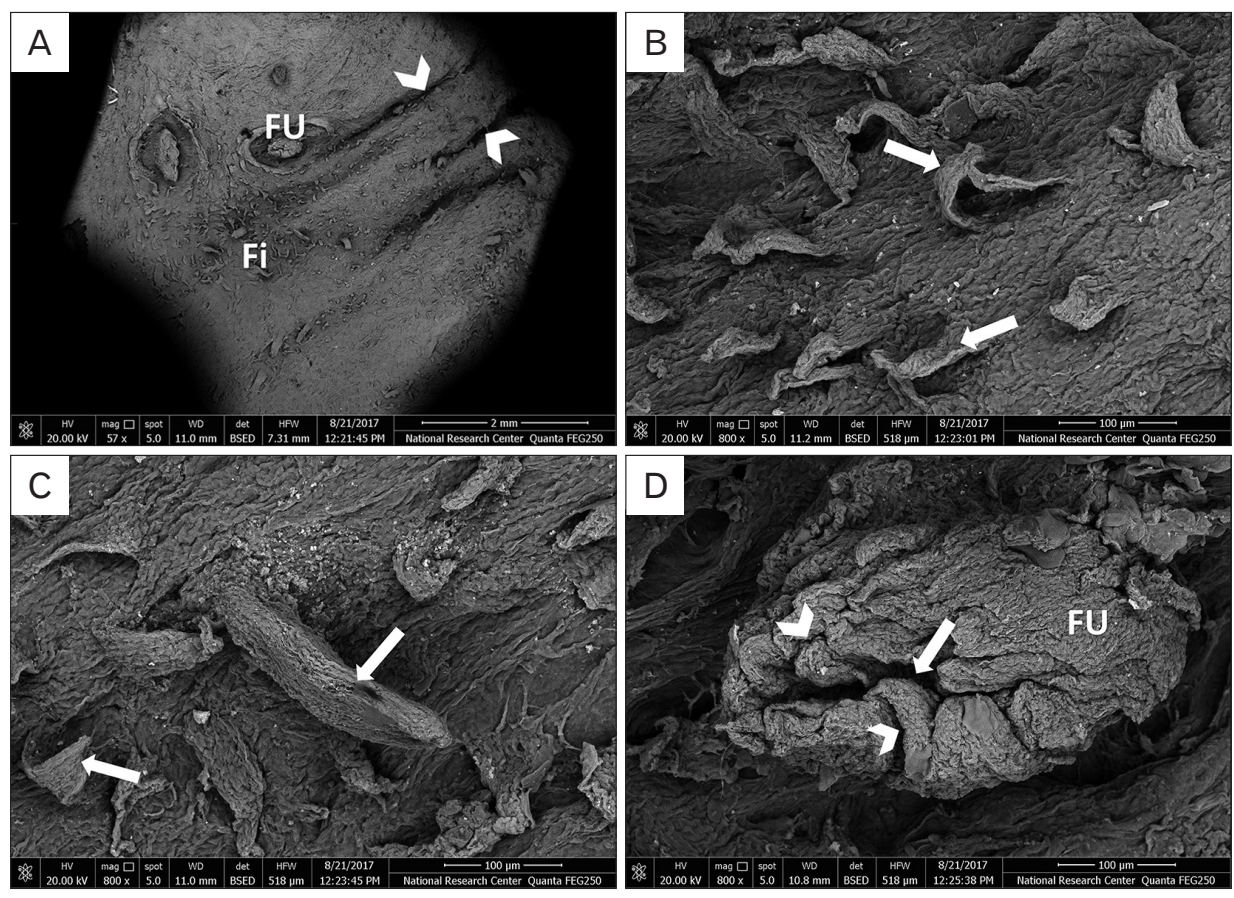

Fig. 3. Scanning electron micrograph of lingual filiform and FU of hedgehogs showing (A) small number of Fi throughout the dorsal surface of the tongue, $\mathrm{FU}$ in posterior part and shallow grooves (arrowheads). (B) Tongue like Fi (arrows) in different directions. (C) Tongue like Fi with different lengths (arrows). (D) Domeshaped FU of an irregular lobulated surface with grooves (arrowheads) and taste pore (arrow). Fi, filiform papillae; FU, fungiform papillae.

ing throughout the tongue with higher distribution in its anterior part than its root. In comparison with the filiform papillae of mice and bats, markedly less distribution of filiform papillae was evident. Few numbers of fungiform papillae were scattered between the filiform papillae and confined to the posterior portion of the tongue (Fig. 3A). The shape of filiform papillae was tongue-like with different lengths and directions but most of them were directed posteriorly. By higher magnification, short and elongated tongue-like filiform papillae were observed (Fig. 3B, C). Dome-shaped fungiform papillae with a lobulated and an irregular surface was noted. Taste pore was also obviously observed on the surface of the fungiform papillae (Fig. 3D).

\section{Discussion}

The distribution of the various papillae on different locations on the dorsal surface of the tongue is a specialty of a genus and is a characteristic feature that varies among various species. Living in different habitats and consuming various diets greatly affect the morphological features, allocation and type of these papillae [20].

In the current study, the dorsal surface of mice tongue was characterized by the presence of a median sulcus. This finding coincides with previous studies which reported that the lingual median sulcus was present in mice [7], bank voles
[21], rabbits [22] and American beaver [23] as it was proved to be one of the characteristic features of their tongues and divides the apex and body portion of the tongue into two equal parts. It was also demonstrated that the median sulcus presented a typical specific feature in many rodents. However, it might vary in size [24]. Moreover, in young albino mice, the median sulcus appeared to extend from the tip to the middle of the back of the tongue [25]. The median sulcus was proved to help in food grinding; when food is put in the mouth, the tongue is depressed along the median sulcus to hold food, then once placed on the tongue, the food is tossed to either side to be grinded by teeth [23]. Findings in bats and hedgehogs revealed the absence of median sulcus as demonstrated in Figs. 2A, 3A. These observations are consistent with and supported by several studies where the authors stated that there is no lingual median sulcus or prominence in the tongue of bats and hedgehogs [26-31].

In the current investigation, the tongue of mice revealed abundant distribution of filiform papillae in the form of four different subtypes (spike, conical, leaf, and tongue-like papillae). These papillae were observed through the entire dorsal surface of the tongue. The direction of these papillae varied according to their location, they were either directed towards the median sulcus or V-shaped sulcus, or directed posteriorly or medially. These results coincide with previous studies where various shapes of filiform papillae were observed in 
rats and mice and occupied different portions of the tongue $[32,33]$. In nature, mice are predominantly herbivores. However, mice began to consume all kinds of food including hard objects as they are mostly adapted to urban regions. Hence, the morphology, distribution and degree of keratinization of tongue papillae vary between mammalian species as they are greatly influenced by dietary habits and environmental circumstances $[34,35]$.

Comparative studies of tongue morphology demonstrated that morphological and functional variations are related to evolutionary shifts in dietary habits of various species [5, 36]. It was demonstrated that frugivorous bats are characterized by having a protruded and elongated tongue. When feeding on fruits, the tongue moves forward to squeeze the bolus against the palate [37]. In the current research, the dorsal surface of bats' tongue was distinguished by a plentiful number of two subtypes of filiform papillae (flower and leaflike types). The different shapes of filiform papillae might be due to different chewing ways and feeding styles $[29,38]$. Flowers' nectar, fruits and fruit juice constitute the diet of the Egyptian fruit bats. These animals are species belonging to the Pteropodidae family and also act as important seed propagators and pollinators [39]. These observations are also in agreement with a previous study which reported that the tongue of bats possessed numerous filiform papillae. In addition, it was found that in some nectar-feeding species, protractile tongues were characterized by having multiple mechanical filiform papillae which form a brush on the tongue apex [40]. Moreover, another study proved that the tongue of Egyptian fruit bat has minute filiform papillae with numerous small tapered processes that are directed posteriorly [26].

The flower-shaped filiform papillae showed a unique morphology and possessed numerous posteriorly directed sharp processes arising from their upper borders. These processes were proved to aid in gripping on fruits [41]. In addition, the tilted orientation of these papillae towards the root of tongue makes retention of food much easier [5]. Interestingly, it was also revealed that these filiform papillae compensate for the absence of incisive teeth as incisors of these bats are placed laterally, leaving an obvious space between canine teeth. This increased space permits the elongated tongue to move freely, thus acting as an adaptation for efficient feeding $[14,42]$. Moreover, the widespread presence and increased surface area of these papillae were proved to enhance oral absorption and effective food transportation [41]. The firm structure of these papillae facilitates effective grinding of fruit pulp. Moreover, they aid in holding the crushed fruit while compressing it against the palate, thus maximizing extraction of juice from fruits [28]. All of these above-mentioned mechanisms allow bats to consume food particles without additional load while flying and control food in the oral cavity while feeding mostly upside-down [28, 43].

Several investigations revealed that filiform papillae possessed a functional role during fights for obtaining food and liquids and their transportation towards the pharynx in addition to their role in improving food adhesion to the tongue surface which is greatly compatible with the dietary habits during the flight. It was also reported that as a consequence of the adaptability of the tongue mucosa to the fluid and semifluid food intake, the morphology and distribution of tongue papillae in Egyptian fruit bat pointed out its specified morphology which distinguishes these species [26, 44, 45].

Moreover, in the present study, the directions of the bats' filiform papillae were observed to be either posterior or medio posterior according to their location. These results could be explained according to a study which reported that the filiform papillae of bats were oriented to be easily bent in the direction towards the base of the tongue, but not in the reverse direction. This could be attributed to the need to convey the food taken into the mouth towards the root of the tongue to be easily swallowed [46]. Similar observations were noticed in the filiform papillae of mice that are present at the tip of the tongue, while those present at the lateral sides and near the median sulcus were directed medially. Same findings were also revealed in long-eared hedgehogs' tongue as most of its filiform papillae were oriented to be easily bent posteriorly towards the root of the tongue.

In the current investigation, the filiform papillae of the hedgehog were tongue-like and fewer in number as compared with those of mice and bats. This is in accordance with a study performed by Naser [47]. In various mammalian species, the lingual papillae showed considerable differences regarding their morphology, dimensions, numbers, distribution and direction of their orientation. These variations are mostly related to the differences in feeding habits and manipulation of food particles in the oral cavity [48].

In addition, it was demonstrated that the filiform papillae form the preliminary pathway of food conveyance which comes into contact with the palate during chewing and deglutition so these papillae possess a good mechanical function. They also supply the tongue with a roughened surface 
suitable for food movement and grinding [49, 50]. Filiform papillae contain no taste buds suggesting that they have no role in taste sensation and have only mechanical function during the masticatory process [50-52]. The different distribution of these papillae emphasizes their function in protecting the dorsal surface of the tongue [50,53].

Regarding the fungiform papillae, findings of the current study showed different shapes of fungiform papillae, cylindrical shape in mice, round or conical shape in bats and dome shape in hedgehogs, all of which were scattered between the filiform papillae. These findings are in agreement with several studies which demonstrated that the size and shape of fungiform papillae differ among various mammalian species $[54,55]$. These observations also coincide with a previous investigation that reported the presence of scattered fungiform papillae in between the long filiform papillae at the posterior portion of the tongue. It was proved that the presence of fungiform papillae in this area can improve taste sensation of the accumulated food in this portion before the swallowing process. Moreover, the presence of filiform papillae around the fungiform papillae, supports their protective function $[56,57]$.

In the present work, the fungiform papillae were characterized by having microgrooves and taste pores containing taste buds. These results are in accordance with many studies which reported that taste buds are considered as peripheral sensory organs of gestation as they have a monitoring function to the chemical environment of the mouth, specially the taste sensation of ingested food [58-60]. Moreover, it was demonstrated that the presence of taste buds on the tongue tip and the fore tongue play an essential role in receiving chemical and mechanical information of food [61].

In conclusion, comparing the ultrastructural morphology and distribution of the lingual filiform and fungiform papillae of the three different mammals under investigation showed remarkable variations among these animals. Such differences were suggested to be correlated with the different environmental circumstances of these animals hence, reflecting the adaptability of these animals to their various dietary habits.

It is recommended to do further investigations regarding the direct effect of the dietary habits and the environmental circumstances on the morphology and distribution of lingual papillae in different animal species. Also, performing morphometrical analysis regarding the size of the studied papillae is highly recommended as it is an important remark in comparative anatomy.

\section{ORCID}

Tahany Haggag: https://orcid.org/0000-0002-7533-2750

Elham F. Mahmoud:

https://orcid.org/0000-0001-8165-5815

Zeinab A. Salem: https://orcid.org/0000-0002-0126-3043

Nermeen AbuBakr:

https://orcid.org/0000-0003-2962-0070

\section{Author Contributions}

Conceptualization: TH, EFM, ZAS, NA. Data acquisition: TH, EFM, ZAS, NA. Data analysis or interpretation: TH, EFM, ZAS, NA. Drafting of the manuscript: TH, EFM, ZAS, NA. Critical revision of the manuscript: TH, EFM, ZAS, NA. Approval of the final version of the manuscript: all authors.

\section{Conflicts of Interest}

No potential conflict of interest relevant to this article was reported.

\section{References}

1. Hussein AJ, Al-Asadi FS. Histological, anatomical and embryonical study of fungiform papillae in tongue of Iraqi sheep. Basrah J Vet Res 2010;9:78-89.

2. Kulawik M, Nienartowicz-Zdrojewska A. The mucous membrane on the ventral surface of the apex and on the lateral surfaces of the body of the tongue in the raccoon dog (Nyctereutes procyonoides). Acta Sci Pol Med Vet 2006;5:67-73.

3. Darwish ST. Comparative histological and ultrastructural study of the tongue in Ptyodactylus guttatus and Stenodactylus petrii (Lacertilia, Gekkonidae). J Am Sci 2012;8:603-12.

4. Herrel A, Canbek M, Ozelmas U, Uyanoğlu M, Karakaya M. Comparative functional analysis of the hyolingual anatomy in lacertid lizards. Anat Rec A Discov Mol Cell Evol Biol 2005;284:561-73.

5. Iwasaki S. Evolution of the structure and function of the vertebrate tongue. J Anat 2002;201:1-13.

6. Carlesso Santos T, Yuri Fukuda K, Plácido Guimarães J, Franco Oliveira M, Angelica Miglino M, Watanabe LS. Light and scanning electron microcopy study of the tongue in Rhea americana. Zoolog Sci 2011;28:41-6.

7. Abd Al-Rhman SA, Al-Fartwsy AR, Al-Shuaily EH. Morphohistological study of the tongue in local mice species by using special stain. J Am Sci 2016;12:13-20. 
8. Jung HS, Akita K, Kim JY. Spacing patterns on tongue surfacegustatory papilla. Int J Dev Biol 2004;48:157-61.

9. Okada S, Schraufnagel DE. Scanning electron microscopic structure of the lingual papillae of the common opossum (Didelphis marsupialis). Microsc Microanal 2005;11:319-32.

10. Kobayashi K, Miyata K, Takahashi K, Iwasaki S. [Threedimensional architecture of the connective tissue papillae of the mouse tongue as viewed by scanning electron microscopy]. Kaibogaku Zasshi 1989;64:523-38. Japanese.

11. Shiels AB, Flores CA, Khamsing A, Krushelnycky PD, Mosher SM, Drake DR. Dietary niche differentiation among three species of invasive rodents (Rattus rattus, R. exulans, Mus musculus). Biol Invasions 2013;15:1037-48.

12. Marshall AG. Bats, flowers and fruit: evolutionary relationships in the Old World. Biol J Linn Soc Lond 1983;20:115-35.

13. Adams RA, Carter RT. Megachiropteran bats profoundly unique from microchiropterans in climbing and walking locomotion: evolutionary implications. PLoS One 2017;12:e0185634.

14. Abumandour MM, El-Bakary RM. Morphological and scanning electron microscopic studies of the tongue of the Egyptian fruit bat (Rousettus aegyptiacus) and their lingual adaptation for its feeding habits. Vet Res Commun 2013;37:229-38.

15. Jabbar AI. Anatomical and histological study of tongue in the hedgehog (Hemiechinus auritus). Int J Recent Sci Res 2014;5:760-3.

16. Massoud D, Lao-Pérez M, Hurtado A, Abdo W, Palomino-Morales R, Carmona FD, Burgos M, Jiménez R, Barrionuevo FJ. Germ cell desquamation-based testis regression in a seasonal breeder, the Egyptian long-eared hedgehog, Hemiechinus auritus. PLoS One 2018;13:e0204851.

17. Kingdon J, Happold D, Hoffmann M, Butynski T, Happold M, Kalina J. Mammals of Africa. London: Bloomsbury, 2013.

18. Qumsiyeh MB. Mammals of the holy land. Lubbock: Texas Tech University Press, 1996. p. 64.

19. Nijman V, Bergin D. Trade in hedgehogs (Mammalia: Erinaceidae) in Morocco, with an overview of their trade for medicinal purposes throughout Africa and Eurasia. J Threat Taxa 2015;7:7131-7.

20. Pastor JF, Barbosa M, De Paz FJ. Morphological study of the lingual papillae of the giant panda (Ailuropoda melanoleuca) by scanning electron microscopy. J Anat 2008;212:99-105.

21. Jackowiak H, Godynicki S. The distribution and structure of the lingual papillae on the tongue of the bank vole Clethrinomys glareolus. Folia Morphol (Warsz) 2005;64:326-33.

22. Abumandour MMA, El-Bakary RMA. Anatomic reference for morphological and scanning electron microscopic studies of the New Zealand white rabbits tongue (Orycotolagus cuniculus) and their lingual adaptation for feeding habits. J Morphol Sci 2013;30:254-65.

23. Shindo J, Yoshimura K, Kobayashi K. Comparative morphological study on the stereo-structure of the lingual papillae and their connective tissue cores of the American beaver (Castor canadensis). Okajimas Folia Anat Jpn 2006;82:127-37.

24. Iwasaki S, Yoshizawa H, Kawahara I. Study by scanning elec- tron microscopy of the morphogenesis of three types of lingual papilla in the rat. Anat Rec 1997;247:528-41.

25. El-Nahass EEM. The morphological development of lingual papillae at prenatal, postnatal, young and adult stages of white albino mouse. J Histol Histopathol 2019;6:6.

26. Jackowiak H, Trzcielińska-Lorych J, Godynicki S. The microstructure of lingual papillae in the Egyptian fruit bat (Rousettus aegyptiacus) as observed by light microscopy and scanning electron microscopy. Arch Histol Cytol 2009;72:13-21.

27. Gregorin R. Comparative morphology of the tongue in freetailed bats (Chiroptera, Molossidae). Iheringia Sér Zool 2003;93:213-21.

28. Mqokeli BR, Downs CT. Palatal and lingual adaptations for frugivory and nectarivory in the Wahlberg's epauletted fruit bat (Epomophorus wahlbergi). Zoomorphology 2013;132:111-9.

29. Massoud D, Abumandour MMA. Anatomical features of the tongue of two chiropterans endemic in the Egyptian fauna; the Egyptian fruit bat (Rousettus aegyptiacus) and insectivorous bat (Pipistrellus kuhlii). Acta Histochem 2020;122:151503.

30. Goodarzi N, Azarhoosh M. Morpholoical study of the Brandt's hedgehog, Paraechinus hypomelas (Eulipotyphla, Erinaceidae), tongue. Vestn Zool 2016;50:457-66.

31. Massoud D, Abumandour MMA. Descriptive studies on the tongue of two micro-mammals inhabiting the Egyptian fauna; the Nile grass rat (Arvicanthis niloticus) and the Egyptian long-eared hedgehog (Hemiechinus auritus). Microsc Res Tech 2019;82:1584-92.

32. Iwasaki S, Miyata K, Kobayashi K. Comparative studies of the dorsal surface of the tongue in three mammalian species by scanning electron microscopy. Acta Anat (Basel) 1987;128:1406.

33. Iwasaki S, Miyata K, Kobayashi K. The surface structure of the dorsal epithelium of tongue in the mouse. Kaibogaku Zasshi 1987;62:69-76.

34. Goździewska-Harłajczuk K, Klećkowska-Nawrot J, Barszcz K, Marycz K, Nawara T, Modlińska K, Stryjek R. Biological aspects of the tongue morphology of wild-captive WWCPS rats: a histological, histochemical and ultrastructural study. Anat Sci Int 2018;93:514-32.

35. Mustapha OA, Ayoade OE, Ogunbunm TK, Olude MA. Morphology of the oral cavity of the African giant rat (Cricetomys gambianus, Waterhouse). Bulg J of Vet Med 2015;18:19-30.

36. Schondube JE, Herrera-M LG, Martínez del Rio C. Diet and the evolution of digestion and renal function in phyllostomid bats. Zoology (Jena) 2001;104:59-73.

37. Freeman PW. Frugivorous and animalivorous bats (Microchiroptera): dental and cranial adaptations. Biol J Linn Soc Lond 1988;33:249-72.

38. Harper CJ, Swartz SM, Brainerd EL. Specialized bat tongue is a hemodynamic nectar mop. Proc Natl Acad Sci U S A 2013;110:8852-7.

39. Aziz SA, Olival KJ, Bumrungsri S, Richards GC, Racey PA. The conflict between pteropodid bats and fruit growers: species, legislation and mitigation. In: Voigt CC, Kingston T, editors. 
Bats in the anthropocene: conservation of bats in a changing world. Cham: Springer Open, 2016. p.377-426.

40. Muchhala N. Nectar bat stows huge tongue in its rib cage. Nature 2006;444:701-2.

41. Abayomi TA, Ofusori DA, Ayoka OA, Odukoya SA, Omotoso EO, Amegor FO, Ajayi SA, Ojo GB, Oluwayinka OP. A comparative histological study of the tongue of rat (Rattus Norvegicus), bat (Eidolon Helvum) and pangolin (Manis Tricuspis). Int J Morphol 2009;27:1111-9.

42. Freeman PW. Nectarivorous feeding mechanisms in bats. Biol J Linn Soc Lond 1995;56:439-63.

43. Leen N, Novick A. The world of bats. New York: Holt, Rinehart and Winston, 1969.

44. Emura S, Hayakawa D, Chen H, Shoumura S, Atoji Y, Wijayanto H. SEM study on the dorsal lingual surface of the large flying fox, Pteropus vampyrus. Okajimas Folia Anat Jpn 2002;79:113-9.

45. Emura S, Okumura T, Chen H. Morphology of the lingual papillae in the Egyptian rousette bat (Rousettus aegyptiacus). Okajimas Folia Anat Jpn 2012;89:61-6.

46. Ciuccio M, Estecondo S, Casanave EB. Scanning electron microscopy study of the dorsal surface of the tongue in Zaedyus pichiy (Mammalia, Xenarthra, Dasypodidae). Int J Morphol 2008;26:13-8.

47. Nasr ES. Surface morphological structure of the tongue of the hedgehog, Hemiechinus Auritus (Insectivora: Erinaceidae). J Am Sci 2012;8:580-8.

48. Abumandour MMA. Morphological comparison of the filiform papillae of New Zealand white rabbits (Oryctolagus cuniculus) as Domestic Mammals and Egyptian fruit bat (Rousettus aegyptiacus) as wild mammals using scanning electron microscopic specimens. Int J Morphol 2014;32:1407-17.

49. Trzcielińska-Lorych J, Jackowiak H, Skieresz-Szewczyk K, Godynicki S. Morphology and morphometry of lingual papillae in adult and newborn Egyptian fruit bats (Rousettus aegyptiacus). Anat Histol Embryol 2009;38:370-6.

50. Karan M, Yilmaz S, Aydin A. Morphology of the filiform lin- gual papillae in porcupine (Hystrix cristata). Anat Histol Embryol 2011;40:100-3.

51. Emura S, Tamada A, Hayakawa D, Chen H, Shoumura S. [SEM study on the dorsal lingual surface of the nutria, Myocastor coypus]. Kaibogaku Zasshi 2001;76:233-8. Japanese.

52. Emura S, Okumura T, Chen H, Shoumura S. Morphology of the lingual papillae in the raccoon dog and fox. Okajimas Folia Anat Jpn 2006;83:73-6.

53. Lauga E, Pipe CJ, Le Révérend B. Sensing in the mouth: a model for filiform papillae as strain amplifiers. Front Phys 2016;4:35.

54. Takemura A, Uemura M, Toda I, Fang G, Hikida M, Suwa F. Morphological study of the lingual papillae in the ferret (Mustela putorius furo). Okajimas Folia Anat Jpn 2009;86:17-24.

55. Parchami A, Salimi M, Khosravi M. Tongue structure in the long-eared hedgehog (Hemiechinus auritus): a scanning electron microscopic study. Vet Res Forum 2018;9:205-9.

56. Jackowiak H. Scanning electron microscopy study of the lingual papillae in the European mole (Talpa europea, L., Talpidae). Anat Histol Embryol 2006;35:190-5.

57. Sohn WJ, Gwon GJ, An CH, Moon C, Bae YC, Yamamoto H, Lee S, Kim JY. Morphological evidences in circumvallate papilla and von Ebners' gland development in mice. Anat Cell Biol 2011;44:274-83.

58. Roper SD. Parallel processing in mammalian taste buds? Physiol Behav 2009;97:604-8.

59. Kumari A, Yokota Y, Li L, Bradley RM, Mistretta CM. Species generalization and differences in Hedgehog pathway regulation of fungiform and circumvallate papilla taste function and somatosensation demonstrated with sonidegib. Sci Rep 2018;8:16150.

60. Mistretta CM, Kumari A. Hedgehog signaling regulates taste organs and oral sensation: distinctive roles in the epithelium, stroma, and innervation. Int J Mol Sci 2019;20:1341.

61. Nasr ES, Gamal AM, Elsheikh EH. Light and scanning electron microscopic study of the dorsal lingual papillae of the rat Arvicanthis niloticus (Muridae, Rodentia). J Am Sci 2012;8:619-27. 